\title{
Comment
}

\section{A Dicotomia entre a Educação e a Formação}

Irineu Correia de Oliveira ${ }^{l}$; Francisco José Chaves da Silva ${ }^{2}$

Resumo: Formar cidadão é desde a antiga Grécia, entretanto, é necessária uma reflexão profunda para compreender como a atividade educativa age com uma formação integrada. O objetivo do trabalho é de refletir sobre a dicotomia entre a educação e formação. O trabalho é cunho bibliográfico, com autores como Tonet (2016), Leal (2012) e outros. O esboço do trabalho dará destaque em primeiro ponto, a educação; em segundo ponto, currículo; Outros pontos de destaque foi a formação dos professores e a dicotomia entre educação e formação humana. O trabalho tem a intenção de enriquecer muito mais as produções cientificas e contribuir para o incentivo de novas pesquisas com a temática proposta.

Palavras Chave: educação. Currículo. Professor. Formação.

\section{The Dichotomy between Education and Training}

\begin{abstract}
Form citizen is since ancient Greece, however, a deep reflection to understand how the educational activity acts with an integrated training is required. The objective is to reflect on the dichotomy between education and training. The work is bibliographic nature, with authors such as Tonet (2016), Leal (2012) and others. The working draft will highlight first point, education; second point, curriculum; Other prominent points was the training of teachers and the dichotomy of education and human development. The work intends to enrich much the scientific production and contribute to the encouragement of new research on the proposed theme.
\end{abstract}

Keywords: education. Curriculum. Teacher. Formation.

\section{Introdução}

A ideia de formar o cidadão não é recente, ocorre desde a antiga Grécia (Paideia), passando para o humanismo renascentista e chegando aos dias atuais, porém, com significado diferente de acordo com o contexto e o tempo. A formação, era privilégio de poucos cidadãos apenas para aqueles de famílias nobres. A educação hoje é para todos.

\footnotetext{
${ }^{1}$ Mestrando em Educação pela Anne Sullivan University. E-mail: irineujackchan@ yahoo.com.br;

${ }^{2}$ Possui Graduação em LICENCIATURA PLENA EM FILOSOFIA pela Universidade Estadual do Ceará-UECE, Pós-Graduação em FILOSOFIA CLÍNICA (UECE), Especialização em METODOLOGIA DO ENSINO DE ARTES (UECE), Capacitação em ARTE-TERAPIA (Instituto Áquilae-2009), e Mestrado em EDUCAÇÃO pela Universidade Federal do Ceará (UFC-2007), DOUTORADO em EDUCAÇÃO pela Unversidade Federal do Ceará-UFC (2010/2014)).
} 
Id on Line Revista Multidisciplinar e de Psicologia

Id on Line Multidisciplinary and Psycology Journal

Esta tem um papel importantíssimo na sociedade, acompanhada de enfoque socializada confirmando as inter-relações humanas e aprendizado, porém muitos têm a dúvida como exatamente ocorre a formação integrada humana. A questão desse estudo é refletir sobre essa temática ao longo desse artigo.

O objetivo é de refletir sobre a dicotomia entre a educação e formação. Isto é, refletir sobre a formulação da identidade profissional e humana.

Tonet (2016) reflete sobre a dicotomia entre educação $r$ formação. Leal (2012) mostra como ocorre a formação dos professores. Outros autores contribuem para o desenvolvimento teórico do trabalho;

O esboço do trabalho é o seguinte: em primeiro, a definição de educação; em seguida, currículo; Outros pontos de destaque foi a formação dos professores e a dicotomia da educação e formação humana.

A proposta da temática colocada neste trabalho, circunscreve no esforço do desempenho que seja construído um significado mais radical e rigoroso para a educação e cidadania.

\section{Educação}

Segundo Vianna (2006, p. 13), a educação, para Aristóteles, deve levar o homem a buscar sua plena realização, porém isso é só possível se ele desenvolver suas faculdades físicas, morais e intelectuais. Os educadores romanos preocupavam-se por questões de ordem prática, não havendo em Roma uma produção, visando desenvolver no indivíduo uma racionalidade que uma nacionalidade que fosse capaz de fazê-lo corretamente, expressando de forma convincente. Na idade Moderna, o filósofo John Locke formulou os princípios educacionais que permanecem até nossos dias. Para ele a educação tinha o papel de ensinar a criança a viver e aprender a exercer a liberdade. Sua visão, é que acriança é educada para si mesma, não é educada para divindade religiosa ou para sociedade.

ZACHARIAS, 2007) Apud Vianna (idem) aborda que para Paulo Freire, educar é construir, libertando o homem do determinismo, passando a reconhecer o papel da História e a questão da identidade cultural, tanto em sua dimensão individual, como na prática pedagógica 
Id on Line Revista Multidisciplinar e de Psicologia

Id on Line Multidisciplinary and Psycology Journal

proposta. A concepção de educação de Paulo Freire percebe o homem como ser autônomo. Esta autonomia está presente na definição de vocação antológica de "ser mais" que está associada com a capacidade de transformar o mundo

De acordo com artigo 2005 da Constituição Federal, a educação é direito de todos, devendo o Estado e a família promove e incentivar com a colaboração da sociedade, visando ao pleno desenvolvimento da pessoa, seu preparo para o exercício da cidadania e sua qualificação para o mercado de trabalho.

\section{Currículo}

Silva (1999) Apud Correia (2007, p. 142) admite que nenhuma definição revele o que é realmente currículo, porém, cada definição revela que determinada teoria define como currículo. Entretanto, currículo é sempre o resultado de uma seleção de conhecimentos e saberes que acabam por constituí-lo e, mais, que sua constituição tem em foco modificar as pessoas que o seguirem.

Popkewitz (1987) Apud Correia (2007, p. 145), refere-se às considerações de que à margem da determinação social, política e econômica dos conteúdos escolares, outras determinações são acrescentadas, agrupando os conteúdos e condicionando nas seguintes categorias: a) os currículos atualmente estão marcados por uma série de ideias provenientes dos movimentos sociais residentes nos séculos XIX e XX, e tem no indivíduo a fé no cultivo de sua razão, a liberação das forças do desenvolvimento pessoal e nas ideias coerentes com o princípio do liberalismo econômico, as bases das ideias pedagógicas; b) a incidência do profissionalismo, transformando em profissões o que eram atividades e contatos menos formalizados entre os seres humanos; c) a força e imposição "de cima para baixo" que a universidade tem; d) a intervenção da psicologia no plano do currículo, é o fundamento à ideia de que o aluno tem uma especialidade como indivíduo no processo de autodesenvolvimento.

Sacristán (1998) Apud Correia (2007, p. 144) destaca que essa mesma sociedade é que se encontram as mudanças que a escolaridade e o currículo, os professores e os materiais didáticos passam a reproduzir a cultura hegemônica favorecendo mais a uns em detrimento de 
Id on Line Revista Multidisciplinar e de Psicologia

Id on Line Multidisciplinary and Psycology Journal

outros, permitindo os espaços relativos de autonomia para o exercício de contra hegemonia, uma posição que passa a uma reflexão $\mathrm{r}$ nos conteúdos selecionados e na forma de abordá-los no ensino.

Moreira; Silva (2001). Apud Correia (idem, p. 144) explica como trata-se da noção de que a educação e o currículo implicam-se essencialmente com as relações de poder que infunde à teorização educacional crítica um caráter eminentemente político. Ao constatar que a ideologia e o currículo não se poderão separar na teorização educacional crítica, propiciando visualizar a cultura e o currículo como inseparáveis já na teoria educacional tradicional, de forma que se constitua uma relação institucionalizada de transmitir a cultura de uma sociedade.

\section{Formação do professor}

O homem é o único ser capaz de estudar, se formando para a sociedade. Esta formação humana resulta de um ato intencional, transformando a criatura biológica em um novo ser, um ser voltado para acultura. $\mathrm{O}$ ato que abordamos é a educação. Entretanto, para essa formação humana necessita de um professor bem capacitado para amenizar todas as dificuldades posta durante a formação do aluno.

De acordo com Leal et al (2012, p. 1) a formação de professores é um processo contínuo, apresentando a pressupostos fundamentados numa promoção do pensamento autônomo e auto formação, considerando as características pessoais, vivências profissionais, histórias de vida, construção de identidade profissional no desenvolvimento pessoal. Além disso, a formação de professores, identidade docente e currículo se configuram em um processo que não são únicos, fixos, unificados, apresentando conexões com as relações de poder, se relacionando a trajetória, percurso, autobiografia.

Corrolo (2007) Apud Leal et al (2012, p. 6-7) afirma que ninguém constrói uma imagem isenta de mudanças sem considerar o outro, que a "construção da identidade é um fenômeno produzido em referência aos outros, considerando critérios de aceitabilidade, de admissibilidade que se fazem por meio da negociação direta com os outros. É um processo de mão dupla, não bastando considerar competente, é necessário que os outros o reconheçam como tal. 
Id on Line Revista Multidisciplinar e de Psicologia

Id on Line Multidisciplinary and Psycology Journal

O autor ainda destaca que a competência é um traço significativo na definição do ser professor e a forma como o professor se vê também é reflexo de como a sociedade de um modo geral o percebe. A tal desvalorização da profissão docente afeta diretamente na formação da identidade profissional do professor. Esta o é reforçada pelo Estado por meio de propagandas, avaliações e modelos de gestão, conduz a função de professor a função burocrática. Assim, afasta do docente as oportunidades para refletir de sua própria prática, contribuindo para a formação de uma identidade não condizente com a valorização da profisssão.

\section{A dicotomia da educação e formação humana}

Tonet (2006, p. 6) considera educação como aquela que deve formar o homem integral indivíduos capazes de pensar com lógica, tendo autonomia moral, tornando cidadãos capazes de contribuir para as transformações sociais, culturais, científicas e tecnológicas, garantindo a paz, o progresso, uma vida saudável e a preservação do nosso planeta. Nesse sentido, a educação tem a missão de gerar pessoas criativas, participativas e críticas. Assim, esse seria um processo permanente, um ideal para ser analisado e discutido, tanto na escola como também fora dela.

Para o autor (Idem, p. 7), a dicotomia é estabelecida de um lado um ideal que estabelece sob a forma de um dever-ser de outro lado, uma realidade objetiva seguindo caminhos próprios, completamente ao contrário as prescrições desse ideal. A teoria pedagógica tradicional, prolonga-se expressividade até os dias atuais, pensa que a tal dicotomia entre ser - dever é algo natural, que não pode ser totalmente eliminada. Portanto, a busca pela melhoria seria o caminho para tentar harmonizar o ideal com a realidade objetiva.

O autor ressalta a questão da dicotomia entre educação e formação humana:

Ora, esta é exatamente a maneira idealista de pensar a questão da relação entre educação e formação humana, ou seja, uma forma que parte do céu para aterra. O estabelecimento do ideal seria uma tarefa do espírito, da consciência, da subjetividade. A realização prática consistiria na tentativa permanente de configurar a realidade, objetiva a partir do que foi estabelecido. (TONET, 2006, p.7).

Quando o autor cita "uma forma que parte do céu para aterra" é um pensamento de Karl Max. Esta usada de forma concreta na educação, age de forma concreta e possibilitando abrir 
Id on Line Revista Multidisciplinar e de Psicologia

Id on Line Multidisciplinary and Psycology Journal

no seu interior para articulação entre educação e a formação humana na atualidade. Além disso, o autor prossegue que Max aborda que não nascemos humanos, e sim, tornamos humanos. Assim, não são as leis biológicas que julga o que devemos fazer para atender nossas necessidades, mas se dando pela apropriação daquilo que se torne patrimônio do gênero humano. Então, nisso descobrimos à educação para o ser-humano.

Adorno (1995) Apud Coelho; Costa (2009, p. 23) considera - se que a educação para a experiência, é também para imaginação, é idêntica àquela para emancipação. É essencial para o homem em sua faculdade de pensamento a capacidade de fazer experiências, através da experiência e da reflexão que se dá a superação da menoridade, constituindo a parte da formação. Assim, a educação para emancipação propicia condições em que os indivíduos conquistem socialmente a autonomia. Entretanto, não se pode deixar de assinalar que qualquer mudança cultural e educacional pressupõe transformações nas relações sociais concretas.

De acordo com Arroyo (1998) Apud Coelho; Costa (2009, p. 24), a escola não é o único espaço de formação de aprendizado e de cultura. $\mathrm{O}$ fenômeno educativo ocorre em outros espaços e tempos sociais, em outras instituições, nas fábricas, nas igrejas e terrenos, nas famílias e empresas, na rua e nos tempos de lazer, de celebração e comemoração, no trabalho. Esta acontece de maneira muito diferenciada.

Tonet $(2008$, p. 2006) reflete sobre a contradição entre o discurso e a realidade objetiva na educação. O primeiro proclama uma formação integral do indivíduo ser livre, participativo, cidadão, crítico para todos os indivíduos. O segundo proclama, no seu movimento real, impossibilitando aquela formação. Assim, a regência encontra-se nas mãos da realidade objetiva, de modo que a realização de uma formação integral jamais pode se transformar em uma afetividade.

\section{Considerações Finais}

Este trabalho teve intuito de mostrar aos leitores que educação e formação são dois processos diferentes de difícil compreensão. O primeiro seria o ideal do dever. $\mathrm{O}$ segundo o real, pois para se conseguir uma formação depende de muitos fatores como esforço, dedicação etc. 
A educação deve propor a efetivação de práticas administrativas e pedagógicas, voltadas para a formação do cidadão. Para isso, é necessário que a escola seja coerente com os princípios éticos da autonomia, da responsabilidade, da solidariedade e do respeito ao bem comum. Além disso, aos princípios políticos dos direitos e deveres da cidadania, do exercício da criticidade e do respeito à ordem democrática.

A educação tem que ter a função de preparar o aluno ao mesmo tempo, para o juízo crítico. Isto é, para esse ter a capacidade de escolher das alternativas propostas pela elite da cidadania, dando a possibilidade de escolher seu próprio caminho. Para isso, os docentes necessitam serem bem preparados para enfrentar os desafios que aparecem no cotidiano dos alunos.

Atualmente, muitos procuram uma formação apenas para adquirir o título, não aprendendo o eficiente e se tornando um profissional com pouco conhecimento. Essa educação comprada empobrece a educação. Isso foi em conta por muitas empresas exigirem formação superior para posições que antes era executada por profissionais com nível de formação fundamental.

A formação humana tem suas problemáticas, sendo um conceito amplo, abrangendo o ser humano em seu desenvolvimento físico, intelectual, psíquico, cultural e social nas relações de educação profissional. Esta merece ser repensada, pois por mais que o indivíduo sofra mudanças por determinações histórico-culturais das construções humanas, trazem em si o potencial de mudança, de crescimento e aprendizagem de cada sujeito.

\section{Referências}

BRASIL. Constituição da República Federativa do Brasil. 40 ed. São Paulo: Saraiva.

COELHO, Maria Inês de Matos; COSTA, Edith Bellico da. A educação e a formação humana: Tensões e desafios na contemporaneidade. Porto Alegre: Artmed, 2009.

CORREIA, Marinêz Luiza. A construção do currículo escolar: respeito à identidade e à subjetividade das teorias na formação educacional do aluno. Educere, 2007. Disponível em: http://www.pucpr.br/eventos/educere/educere2007/anaisEvento/arquivos/PO-015-03.pdf

LEAL, Cristianni Antunes. Reflexões sobre currículo na escola: proposta para formação/reformulação da identidade profissional do professor. ENDIPE - Encontro Nacional de Didática e Práticas de Ensino - UNICAMP - Campinas - 2012. Disponível em: 
http://www.infoteca.inf.br/endipe/smarty/templates/arquivos_template/upload_arquivos/acerv o/docs/3558p.pdf

TONET, Ivo. Educação e formação humana. Maceió, 2006. Disponível em: http://ivotonet.xpg.uol.com.br/arquivos/EDUCACAO_E_FORMACAO_HUMANA.pdf. Acessado em 30 de 4 de 2006.

VIANNA, Carlos Eduardo Souza. Evolução histórica do conceito de educação e os objetivos constitucionais da educação brasileira. Janus, lorena, ano $3, \mathrm{n}^{\circ} 4,2006$. Disponível em: http://publicacoes.fatea.br/index.php/janus/article/viewFile/41/44

\section{Como citar este artigo (Formato ABNT):}

OLIVEIRA, I.C.; SILVA, F.J.C. A Dicotomia entre a Educação e a Formação. Id on Line Revista Multidisciplinar e de Psicologia, Janeiro de 2017, vol.10, n.33, Supl 2. p. 66-73. ISSN: 1981-1179.

Recebido: 11/12/2016

Aceito: 23/12/20176 